convenient roll tops are now available. The gelatinous hydroxides, which are precipitated in the sweat ducts, may linger on for a while, and treatment every two or three weeks may often suffice.

The Hurley-Shelley operation is used less often now. Ellis and Scurr, with experience of this operation on some 200 patients, used the aluminium mixture on a further 42 patients all of whom were ready to submit to surgery. Only four of these eventually had an operation, all because of persistent soreness and irritation from the lotion. ${ }^{11}$

But if axillary hyperhidrosis can now be dealt with fairly well, with an effective and safe operation available for the minority of patients who cannot tolerate the aluminium chloride mixture, the same cannot be said for palmar sweating. Clearly conservative measures should be used if possible, but the results of using both tranquillisers and systemic anticholinergics, with all their side effects, have usually been disappointing. In the past topical applications have not had much success either, but there have recently been reports of good results with methenamine (hexamine) ${ }^{14}$ and with nightly applications of the alcoholic aluminium chloride hexahydrate mixture. ${ }^{15}$ This general failure of topical applications led to efforts to drive the chemicals into the skin electrically with iontophoresis and to the surprising finding that ordinary tap water acts almost as well as any of these solutions and at the same time avoids systemic side effects. Levit has given a clear account of the practical details of tap water iontophoresis. ${ }^{16}$ Once a reduction in sweating has been obtained treatment every few weeks may suffice, and patients may then avoid endless trips to hospital by acquiring a simple and effective apparatus to use themselves at home.

Other techniques such as biofeedback and conditioning ${ }^{17}$ are still in their infancy but may offer some hope in the future. At present, however, if a fair trial of the above methods has not helped then sympathectomy should be considered. An operation which may require exploration through important deep structures in the neck or the removal of parts of the ribs should never be undertaken lightly. Various surgical approaches are available, but the supraclavicular route seems to carry an especially high risk of causing Horner's syndrome, ${ }^{3}$ and Kux's endoscopic technique ${ }^{4}$ is perhaps the least traumatic. Sympathectomy denervates the sweat glands not just of the palm but of up to one fifth of the body surface, ${ }^{18}$ and compensatory sweating in other areas may become a problem. Despite this, patients relieved of their wet hands are kind about the operation, and the long term results are usually satisfactory.

J A SAVIN

Consultant Dermatologist,

Royal Infirmary,

Edinburgh EH3 9YW

' Lerer B, Jacobowitz J, Wahba A. Personality features in essential hyperhidrosis. Int F Psychiatry Med 1980;10:59-67.

Maple S, Bradshaw CM, Szabadi E. Pharmacological responsiveness of sweat glands in anxious patients and healthy volunteers. Br $\mathcal{F}$ Psychiatry $1982 ; 141: 154-61$.

"Adar R, Kurchin A, Zweig A, Mozes M. Palmar hyperhidrosis and its surgical treatment. A report of 100 cases. Ann Surg 1977;186:34-41.

' Kux M. Thoracic endoscopic sympathectomy in palmar and axillary hyperhidrosis. Arch Surg 1978;113:264-6.

Hurley $\mathrm{HJ}$, Shelley WB. A simple surgical approach to the management of axillary hyperhidrosis. $7 A M A$ 1963;186:109-12.

'Bergkvist L, Engevik L. The surgical treatment of axillary hyperhidrosis. Br F Surg 1979;66:482-4.

Andersen EB, Burchardt $\mathrm{H}$, Taarnhøj P. Axillary hyperhidrosis. $\mathcal{F} A M A$ $1975 ; 231: 1026-7$

* Bretteville-Jensen G, Mossing N, Albrechtsen R. Surgical treatment of axillary hyperhidrosis in 123 patients. Acta Derm Venereol (Stockh) $1975 ; 55: 73-7$.
9 Ashby EC, Williams JLI. Cryosurgery for axillary hyperhidrosis. $\mathrm{Br} \mathrm{Med} \mathcal{f}$ $1976 ;$ ii :1173-4.

10 Ellis H. Axillary hyperhidrosis ; failure of subcutaneous curettage. $\mathrm{Br} \mathrm{Med} \mathfrak{f}$ 1977;ii:301-2.

11 Ellis H, Scurr JH. Axillary hyperhidrosis-topical treatment with aluminium chloride hexahydrate. Postgrad Med $\mathcal{f}$ 1979;55:868-9.

12 Scholes KT, Crow KD, Ellis JP, Harman RR, Saihan EM. Axillary hyperhidrosis treated with alcoholic solution of aluminium chloride hexahydrate. Br Med F 1978;ii:84-5.

${ }^{13}$ Shelley WB, Hurley HJ Jr. Studies on topical antiperspirant control of axillary hyperhidrosis. Acta Derm Venereol (Stockh) 1975;55:241-60.

14 Cullen SI. Topical methenamine therapy for hyperhidrosis. Arch Dermatol 1975;111:1158-60.

15 Jensen O, Karlsmark T. Palmoplantar hyperhidrosis. Treatment with alcoholic solution of aluminium chloride hexahydrate: a simple method of transpiration measurement. Dermatologica 1980;161:133-5.

${ }^{16}$ Levit F. Treatment of hyperhidrosis by tap water iontophoresis. Cutis $1980 ; 26: 192-4$

17 Duller P, Gentry WD. Use of biofeedback in treating chronic hyperhidrosis: a preliminary report. Br $\mathcal{F}$ Dermatol 1980;103:143-6.

${ }^{18}$ Shoenfield Y, Shapiro Y, Machtiger A, Magazanik A. Sweat studies in hyperhidrosis palmaris and plantaris. A survey of 60 patients before and after sympathectomy. Dermatologica 1976;152:257-62.

\section{Locking up patients with psychiatric illness}

Most inpatients with psychiatric illness are treated in open wards, ${ }^{1}$ but for a time a few may be nursed in seclusion. ${ }^{2}$ The latter is defined as the containment of a patient alone in a room or enclosed area from which he has no way out ${ }^{3}{ }^{4}$; today such restraint is used in psychiatric hospitals, ${ }^{5}$ secure units, and special hospitals. ${ }^{7}$

Seclusion is carried out in two main circumstances: firstly, in an emergency to help cope with disturbed behaviour; and, secondly, and probably much less commonly, with the patient's consent in behaviour modification programmes. ${ }^{48}$ Occasionally, however, there is no clear cut difference between these two activities, but whatever the reason the result is that an ill person may be isolated from human contact in a bare room for an unspecified period. Although prison rules govern removal from association and the use of solitary confinement, there is no statutory control of these procedures in the National Health Service. Moreover, the Department of Health and Social Security guidelines on the management of violent or potentially violent patients ${ }^{9}$ have been criticised for their inadequacy. ${ }^{10}$

Doctors have a clear responsibility to prevent abuses of seclusion. ${ }^{2}$ In 1974 a patient at the Broadmoor special hospital alleged that he was locked up by himself almost continuously for five weeks in a dirty room with a plastic mattress and no furniture on a stone or concrete floor. He was dressed in pyjamas, with no footwear. The ventilation was said to be inadequate and the room had no toilet facilities, except for two plastic chamberpots, which showed signs of use by a previous occupant. During his first week in the room the patient was not provided with toilet paper, only pieces of newspaper. His complaint of inhumane and degrading treatment was investigated by the European Commission of Human Rights (application number 6840/74): and subsequently, in 1979, new working guidelines concerning seclusion were introduced at Broadmoor. ${ }^{11}$ Nevertheless, such cases rarely come to public notice. ${ }^{712} 13$ Indeed, few papers have been published on the theoretical basis ${ }^{14-16}$ and clinical use of seclusion. ${ }^{16-19}$ Estimates from the United States are that between $4 \% \%^{7}$ and $26 \%{ }^{16}$ of general psychiatric inpatients are secluded in the course of their hospital admission. This action 
is usually taken because the patient is violent, unresponsive to standard treatment, and is hazarding the safety of the ward environment. A senior nurse normally makes the initial decision to begin seclusion and a doctor makes an assessment later. Typically, secluded patients have schizophrenia or mania: other diagnoses are less frequent. As a group secluded patients are significantly younger and stay in hospital longer than non-secluded patients. ${ }^{16} 18$ There are few other differences between the two groups.

The use of seclusion in practice is described in a report from a 25 bed long stay British ward for disturbed and aggressive women. ${ }^{19}$ In a year there were 69 episodes of seclusion, affecting 15 patients. In half of the incidents seclusion lasted for less than an hour; the average duration was two and a half hours and the longest period 23 hours. Peak occasions for seclusion were mealtimes and days when there was a change of nursing shifts. About half the patients were settled or asleep while in seclusion, but the rest kept up a disturbance. In a quarter of the episodes patients continued to be disruptive after seclusion; nevertheless, generally seclusion was succeeded by quiet behaviour.

There is probably some truth in the belief that seclusion secures "an irritable brain from causes of increased irritability." "20 Nevertheless, its benefits, when they occur, are more likely to be due to appropriate medication and attention from staff. Moreover, like many medical interventions, seclusion may also have adverse effects. In one study of 63 patients such difficulties were noted in 30 cases $^{18}: 19$ patients assaulted staff; eight deliberately injured themselves; four destroyed the room; in four the mental state deteriorated; and three patients deteriorated physically because of unrecognised organic conditions. Finally, in no fewer than 16 of the 63 cases few or no medical records were kept of the seclusion.

As a minimum safeguard hospitals should always have strict regulations about the use of seclusion; these should include the requirement that secluded patients are visited routinely and often by medical and nursing staff. Each of the special hospitals has an established procedure for using and recording seclusion, and similar arrangements apply in mental hospitals. ${ }^{112122}$ None the less, both in Parliament and in the National Health Service concern is still being expressed about the use of seclusion. ${ }^{22}$ Perhaps this concern should also be linked to recognising that the National Health Service has to find ways of treating more of its disruptive and aggressive patients without resorting to bans on admission or relying on the prison service. ${ }^{23} 24$ Finally, because an excessive use of seclusion may, say, be a consequence of a shortage of nursing staff, ${ }^{412}$ or of a failure to consider other forms of psychiatric treatment, I welcome that the commission considering the new Mental Health Act is expected to take a close interest in it. ${ }^{22}$

GREG WILKINSON

Senior Registrar,

Maudsley Hospital,

London SE5 8AZ

(now Research Psychiatrist,

MRC Unit for Epidemiological

Studies in Psychiatry,

University Department of Psychiatry,

Royal Edinburgh Hospital,

Edinburgh EH10 5HF)

Public Policy Committee of the Royal College of Psychiatrists. Locked wards and informal patients. Bulletin of the Royal College of Psychiatrists $1980 ;$ Jan :8-9.

Royal College of Psychiatrists. Isolation of patients in protected rooms during psychiatric treatment. Bulletin of the Royal College of Psychiatrists $1981 ; 5: 96$.
${ }^{3}$ Anonymous. Locking up patients by themselves. Bulletin of the Royal College of Psychiatrists 1982;6:199-200.

4 Royal College of Nursing: Society of Psychiatric Nursing. Seclusion and restraint in hospitals and units for the mentally disordered. London: Royal College of Nursing of the United Kingdom, 1979.

5 Strutt R, Bailey C, Peermohamed R, Forrest AJ, Corton B. Seclusion: can it be justified? Nursing Times 1980;76:1629-33.

' Higgins J. Four years' experience of an interim secure unit. $\mathrm{Br} \mathrm{Med} \mathcal{f}$ $1981 ; 282: 889-93$.

${ }^{7}$ Department of Health and Social Security. Report of the review of Rampton Hospital. London: HMSO, 1980.

8 Royal College of Psychiatrists, Royal College of Nursing, and the British Psychological Society. Behaviour modification. London: HMSO, 1980.

- Department of Health and Social Security. The management of violent, or potentially violent, hospital patients. London: DHSS, 1976. (HC(76)11.)

10 Confederation of Health Service Employees. The management of violent or potentially violent patients. Banstead: Confederation of Health Service Employees, 1977.

11 Young G. Parliamentary written reply. House of Commons official report (Hansard) 1980 Jan 25-31;977:cols 257-9. (No 1158.)

12 Department of Health and Social Security. Report of the committee of inquiry into Normansfield Hospital. London: HMSO, 1978.

${ }^{13}$ Royal College of Psychiatrists. The Normansfield Hospital inquiry. Bulletin of the Royal College of Psychiatrists 1979;Oct:146-7.

14 Gutheil TG. Observations on the theoretical bases for seclusion of the psychiatric inpatient. Am f Psychiatry 1978;135:325-8.

15 Gutheil TG. Restraint versus treatment: seclusion as discussed in the Boston state hospital case. Am f Psychiatry 1980;137:718-9.

16 Plutchik R, Karasu TB, Conte HR, Siegel B, Jerrett I. Toward a rationale for the seclusion process. $\mathcal{F}$ Nerv Ment Dis 1978;166:571-9.

17 Wells DA. The use of seclusion on a university hospital psychiatric floor. Arch Gen Psychiatry $1972 ; \mathbf{2 6}: 410-3$.

${ }^{18}$ Mattson MR, Sacks MH. Seclusion: uses and complications. $A m \mathcal{f}$ Psychiatry 1978;135:1210-3.

19 Campbell W, Shepherd H, Falconer F. The use of seclusion. Nursing Times $1982 ; 78: 1821-5$.

${ }^{20}$ Conolly J. Treatment of the insane without mechanical restraints (1856). Reprinted, and introduced by Hunter R, Macalpine I. Folkestone and London: Dawsons of Pall Mall, 1973.

21 The Bethlem Royal Hospital and the Maudsley Hospital. Procedure for the seclusion of patients in the joint hospital. London: The Bethlem Royal Hospital and the Maudsley Hospital House Governor's Office, 1982.

22 Davis T. Parliamentary written reply. House of Commons official report (Hansard) 1982 Dec $6 ; 33: \operatorname{col} 398$. (No 24.)

${ }^{23}$ Bluglass $\mathrm{R}$. Regional secure units and interim security for psychiatric patients. Br Med F 1978; :489-93.

${ }^{24} \mathrm{Orr} \mathrm{JH}$. The imprisonment of mentally disordered offenders. $\mathrm{Br} \mathcal{F}$ Psychiatry 1978;133:194-9.

\section{Double indemnity in oesophageal carcinoma?}

Oesophagectomy for cancer has a mortality reaching $30 \%$ in some series-the highest mortality of any routinely performed $\frac{\rho}{3}$ operation. ${ }^{1}$ Incomplete excision of the tumour and its microscopic local extensions exposes the patient to this high operative risk for little benefit; for if he survives long enough $\stackrel{N}{\sigma}$ he will develop a recurrence of malignant dysphagia. The longi- $-\frac{7}{0}$ tudinal extent of spread of oesophageal squamous cancinoma has been well studied, and skip lesions occur at a distance from $\stackrel{\mathcal{N}}{\mathrm{N}}$ the main tumour. ${ }^{2}$ Histological examination of frozen sections $\stackrel{\omega}{2}$ has been advocated during surgical resection to determine if the cut ends are clear of tumour, ${ }^{34}$ but the histologist cannot $\stackrel{0}{\overline{0}}$ examine the whole oesophageal circumference within a $\stackrel{\oplus}{\oplus}$ reasonable time limit, and he may miss small skip lesions. A minimum clearance of $12 \mathrm{~cm}$ from macroscopically detectable growth was advocated 20 years ago. ${ }^{5}$ Nevertheless, one quarter of all resections are still thought to be incomplete. ${ }^{6}$

Several authors have emphasised the extraoesophagealo spread of carcinoma as seen in operation specimens ${ }^{2}$ and at 8 necropsy. ${ }^{7}$ Logan in Edinbugh attempted the first radicalo resections with block dissection of the adjacent connective tissues and lymph nodes. ${ }^{8}$ Radiological studies have shown, $\stackrel{?}{\rightleftharpoons}$ 